\title{
ANÁLISE DO POTENCIAL TURÍSTICO DOS MUNICÍPIOS DA AMREC - ASSOCIAÇÃO DOS MUNICÍPIOS DA REGIÃO CARBONÍFERA DO SUL DO ESTADO DE SANTA CATARINA
}

\author{
ANALYSIS OF THE TOURIST POTENTIAL OF THE REGION SOUTH \\ STATE OF SANTA CATARINA
}

\author{
Ricardo Pieri ${ }^{1}$ \\ Nilzo Ivo Ladwig ${ }^{2}$
}

\begin{abstract}
Resumo
Este trabalho teve como objetivo analisar o potencial dos atrativos turísticos do patrimônio histórico e cultural dos municípios da AMREC (Associação dos Municípios da Região Carbonífera), sob a ótica dos responsáveis pela operacionalização do turismo em cada município, com a finalidade de propor um desenvolvimento integrado regional. A pesquisa caracteriza-se como quantitativa, exploratória e estudo de caso, com utilização da pesquisa bibliográfica, documental e de campo. O instrumento de pesquisa foi desenvolvido com base no Inventário de Oferta Turística INVTUR do Ministério do Turismo do Brasil. A quantificação dos atrativos turísticos (naturais e históricoculturais), dos empreendimentos turísticos (equipamentos e instalações), da infraestrutura de apoio ao turismo e dos organismos especializados, públicos e privados, confirmaram a existência do potencial turístico da região. Demonstrou-se a existência de uma infraestrutura que dá apoio ao turismo, no que diz respeito à comunicação e ao transporte. Quanto aos equipamentos turísticos, percebe-se que há uma concentração maior no município de Criciúma, que é o polo regional, e que alguns municípios estão em um processo de incentivar o desenvolvimento desses equipamentos. Assim, pelos resultados da pesquisa, pode-se considerar que a região tem atrativos turísticos, infraestrutura e empreendimentos turísticos para experimentar um crescimento turístico.
\end{abstract}

Palavras-chave: Turismo Regional; Inventário Turístico; Patrimônio Turístico

\begin{abstract}
This study aimed to identify and quantify the potential historical and cultural heritage tourist attractions of the AMREC (Associação dos Municípios da Região Carbonífera) counties, under the perspective of those responsible for the tourism operation in each county, with the purpose of proposing an integrated regional development. The research is characterized as quantitative, exploratory and a study case, with the use of a bibliographic, documentary and field research. The research instrument was developed based on the tourist offer inventory INVTUR of the Brazilian Tourism Ministry. The quantification of the tourist attractions (natural and historical cultural), tourist enterprises (equipment and facilities), infrastructure that support tourism and the specialized public and private bodies, confirmed the existence of tourism potential of the region. The existence of an infrastructure that supports tourism was demonstrated, regarding communication and transport. As for tourist facilities, it is perceived that there is a higher concentration in the Criciúma county, which is the regional pole, and that some counties are in the process of encouraging the development of such equipment.

\footnotetext{
${ }^{1}$ Professor do Curso de Graduação em Tecnologia em Gestão Financeira - UNESC (Universidade do Extremo Sul Catarinense).

2 Professor do Curso de Engenharia de Agrimensura e Programa de Pós Graduação em Ciências Ambientais - UNESC (Universidade do Extremo Sul Catarinense), Professor da UNISUL (Universidade do Sul de Santa Catarina), e-mail: ladwig@unesc.net
} 
Therefore, by the results of the research, one can consider that the region has tourist attractions, infrastructure and tourism enterprises to experience a tourism growth.

Keywords: Regional Tourism; Tourist inventory; Tourism heritage

\section{Introdução}

A atividade turística está nos planos estratégicos da maioria dos governantes dos municípios que compõem a Associação dos Municípios da Região Carbonífera (AMREC), no sul do estado de Santa Catarina. O turismo é visto atualmente como um possível propulsor do desenvolvimento econômico e social da região. Esse é um discurso comum entre os prefeitos da Região, que cada vez mais apontam para as potencialidades turísticas de seus municípios, manifestando a vontade de explorá-las.

Os municípios da AMREC estão localizados no Sul do estado de Santa Catarina, na mesorregião denominada pelo IBGE como Sul Catarinense. De acordo com a FECAM (2012), Santa Catarina é dividida pelo Instituto Brasileiro de Geografia e Estatística - IBGE em seis mesorregiões: Norte, Oeste, Serrana, Vale do Itajaí, Grande Florianópolis e Sul que, por sua vez, organizam-se politicamente por Associações de Municípios.

A AMREC é uma associação composta pelos seguintes municípios do Sul de Estado de Santa Catarina: Balneário Rincão; Cocal do Sul; Criciúma; Forquilhinha; Içara; Lauro Müller; Morro da Fumaça; Nova Veneza; Orleans; Siderópolis; Treviso e Urussanga. (AMREC, 2014). Trata-se de uma entidade com personalidade jurídica de direito privado, sem fins lucrativos, de natureza civil, que visa à integração administrativa, econômica e social dos municípios da região carbonífera do Sul do estado de Santa Catarina.

A população total estimada na região para 2013, segundo o IBGE, é de 411.584, sendo que a cidade de Criciúma possui 202.395, correspondendo a 49,2\% do total de habitantes da região. Criciúma é o polo regional e tem a maior densidade demográfica entre os municípios pertencentes à AMREC, com $815 \mathrm{hab} / \mathrm{km}^{2}$. Em termos populacionais, a segunda maior cidade da região é Içara, com 51.416 habitantes. Na sequência, temos as cidades de Forquilhinha, Orleans e Urussanga, com um número de habitantes semelhantes, ou seja, 24.256, 22.171 e 20.826, respectivamente. O município com menor número de habitantes é Treviso, com 3.706 e densidade demográfica de 22 $\mathrm{hab} / \mathrm{km}^{2}$, também a menor da região. 
O total da área territorial da região é de $2.654,87 \mathrm{~km}^{2}$ e a densidade demográfica média é de $155 \mathrm{hab} / \mathrm{km}^{2}$. O município com a maior área territorial é Orleans, com $548,79 \mathrm{~km}^{2}$.

A região está localizada entre a serra geral do Sul do estado e o mar. Os municípios de Orleans, Lauro Müller, Treviso, Siderópolis e Nova Veneza fazem divisa com a Serra e alguns têm áreas no costão da serra. Esta proximidade propicia um inverno rigoroso na região, possibilitando a exploração de atividades desta estação e é roteiro para turistas que sobem a serra, a fim de aproveitar o turismo de inverno.

A posição estratégica dos municípios permite uma observação da paisagem privilegiada da serra e da exuberância da Mata Atlântica. Por outro lado, há também a proximidade com o mar. O município de Balneário Rincão possui $13 \mathrm{~km}$ de praia, o que permite temperatura ideal no verão para o aproveitamento de toda a sua extensão para a prática das demais atividades que o verão proporciona.

Há municípios com maior desenvolvimento no segmento turístico, procurando incentivar investimentos e iniciativas nesta área específica, como exemplo dessas iniciativas, pode-se citar: a Rota Gastronômica em Nova Veneza; o Vale das Uvas Goethe em Urussanga e a Mina de Visitação em Criciúma. Por outro lado, segundo Fabre (2009), as ações de cada município são isoladas, ou seja, cada um procura desenvolver atividades, ações e investimentos dentro de seus limites territoriais. Não há um olhar regional da complementação e/ou utilização da infraestrutura de apoio, serviços e equipamentos ou atrativos turísticos existentes regionalmente.

Dentro da política de regionalização do Governo Federal - Ministério do Turismo - e implementada pelo Governo Estadual, os municípios da AMREC fazem parte da Região Turística denominada Encantos do SUL (SOL, 2012), que procura incentivar e organizar o turismo regional. Para potencializar o turismo destes municípios, há a necessidade da realização do planejamento turístico regional, que passa por análise do ambiente (interno e externo), definição de foco, estabelecimentos de estratégias e o desenvolvimento dos planos de ação (MTur, 2008c).

Ribeiro (2000) afirma que o turismo é um fenômeno socioeconômico centrado na prestação de serviços, compostos por atrativos culturais e naturais como produtos oferecidos e deve ser levado a sério quanto ao desenvolvimento, continuidade e aplicação. Muitas regiões brasileiras não se desenvolvem em termos turísticos por falta de clareza em políticas de desenvolvimento e harmonia entre os setores públicos e privados. O autor afirma, ainda, que no processo inicial para o planejamento do turismo 
municipal, pode-se contar com uma ferramenta denominada de inventário da oferta turística, instituído pela Organização Mundial do Turismo (OMT). O inventário possibilita diagnosticar a situação do município, região ou zona de forma ampla, gerando dados físicos, humanos, econômicos e sociais para a articulação do processo de planejamento e consequente desenvolvimento da atividade.

A região estudada apresenta poucas informações a respeito do turismo, quer seja no âmbito dos municípios, quer seja na própria Associação dos Municípios da Região Carbonífera (AMREC). Em função disso, a AMREC contratou a Sociedade de Assistência aos Trabalhadores do Carvão (SATC) para realizar um estudo e identificar as potencialidades turísticas da região, os resultados foram apresentados em 02 de julho de 2014 (LIMA, 2014).

O trabalho realizado pela SATC levantou potencialidades do turismo regional, com relação aos atrativos turísticos, apontando para potenciais rotas regionais, o que é fundamental e contribui para o planejamento do turismo da região. Apesar do avanço, a carência por informações ainda é significativa, pois não há informações disponíveis sobre infraestrutura de apoio, serviços e equipamentos turísticos da região. Para um planejamento adequado, há a necessidade de identificar e quantificar outros elementos que compõem o patrimônio turístico local.

Diante do que foi exposto e considerando as potencialidades turísticas da região, este trabalho tem como objetivo geral: analisar o potencial dos atrativos turísticos do patrimônio histórico e cultural dos municípios da AMREC.

\section{O Turismo como Sistema}

O turismo é uma atividade de base cultural, despertada pelo interesse das pessoas em conhecer os costumes, religiões, arte, paisagem, arquitetura, enfim, conhecer a maneira de vida de outras pessoas ou regiões, na sua forma presente ou no passado, entendendo como vivem ou viviam as pessoas em determinado momento. Trata-se de um processo de interação contínua de conhecimento de espaços e culturas atraentes entre comunidades diferentes que ocupam espaços distintos e socialmente construídos. Por apresentar essa diversidade, tornam-se atraentes para o conhecimento do outro - o turista, aquele que viaja para conhecer novos locais, para descansar, para espairecer em um ambiente diferente daquele onde tem sua moradia (DIAS, 2006). 
Para Rodrigues (1999), o turismo é um fenômeno econômico, político, social e cultural dos mais expressivos da sociedade pós-industrial e movimenta, em nível mundial, um grande volume de pessoas e capital, participando de forma cada vez mais significativa ao criar e recriar espaços diversificados.

Segundo Boullón (2002), o turismo é uma consequência de um fenômeno social cujo ponto de partida é a existência do tempo livre e o desenvolvimento dos sistemas de transporte. $\mathrm{O}$ autor afirma ainda que em torno de viagens realizadas para $\mathrm{o}$ aproveitamento do tempo ocioso, foram se agregando uma série de atividades, como forma de resolver os problemas das pessoas, incorporando-se serviços destinados a aumentar o conforto e possibilitar oportunidades de lazer ao turista, com ações em um primeiro momento da iniciativa privada e, posteriormente, com o engajamento do poder público.

Dessa forma, foi formando-se uma rede de relações ao redor do turismo para dar suporte ao seu funcionamento, o que acabou originando um sistema com algumas facetas ou modelos, como: Oferta-demanda - centra interesse no funcionamento do chamado turismo comercial apresentado na Figura 1 e detalhado na sequência; Antropológico social - ocupa-se das manifestações do ócio e do tempo livre nas diversas sociedades e analisa suas repercussões nas condutas individuais e coletivas; Turismo Industrial - interessa a produção de massa, a comercialização e o lucro.

$\mathrm{Na}$ figura 1, pode-se observar as partes integrantes do sistema turístico e suas relações com base no modelo oferta-demanda. À esquerda da figura, encontra-se o ponto inicial do sistema com o encontro da oferta e demanda dos produtos turísticos, que, junto com a infraestrutura, compõem a estrutura de produção do setor, na parte direita da figura. No centro, consta a superestrutura turística, que tem por função o controle e eficiência do sistema, fiscalizando seu funcionamento e as inter-relações das partes (BOULLÓN, 2002).

Figura 1: Elementos que compõem o sistema turístico 


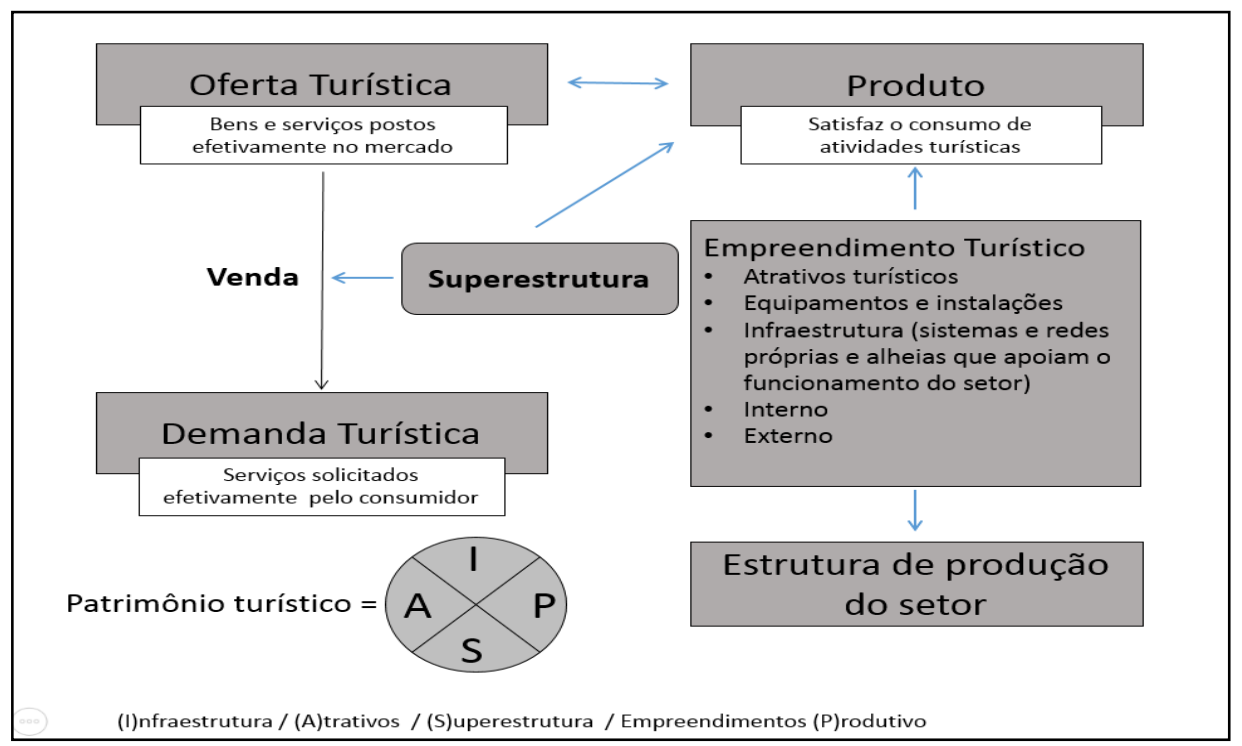

Fonte: Adaptado de Boullón (2002, p. 38)

Para o MTur (2008a), o turista é o agente econômico gerador do consumo, assim, o valor e a qualidade dos produtos e serviços ofertados devem estar de acordo com as necessidades, demandas e desejos dos mesmos.

A demanda turística é representada pelo total de turistas que são atraídos para uma determinada região, país, zona, centro turístico ou atrativos. Para melhor gerenciar a produção do setor de turismo é importante que se possa quantificar a geração da receita em cada um dos centros turísticos que o compõem. Assim, a demanda total de um país ou região é representada pela soma das demandas correspondentes a cada um dos centros turísticos que ela contém (BOULLÓN, 2002). Para Beni (2008), a demanda representa a quantidade de bens e serviços que os consumidores desejam e têm condições de comprar por um certo preço em um determinado período de tempo.

A oferta turística é a quantidade de bens e serviços que são disponibilizados em um mercado consumidor. De acordo com Beni (2008), a oferta turística é constituída pelo conjunto de recursos naturais e culturais, de bens e de serviços (como: alojamento, alimentação, recreação e lazer) com potencial de atrair e reter em uma determinada região, durante um certo período de tempo, um público visitante.

O encontro da oferta com a demanda turística se dá por meio do processo de compra e venda, lembrando que, no turismo, o consumidor se desloca ao local geográfico onde se localiza a oferta, e não ao contrário (BOULLÓN, 2002, p. 44).

Para Beni (2008, p.167), no mercado do turismo, os produtos não são homogêneos e intercambiáveis, mas diferenciados, pois, cada um vende um produto que, de certo modo, é diferenciado dos demais, o que poderia se assemelhar a um 
monopólio, em função desta diferenciação. Em função disso, o mercado tem certa capacidade de variar os preços, ou seja, as pessoas estão dispostas a pagar um pouco mais por um produto melhor, ou por visitar um local espetacular. Por outro lado, se os preços subirem demais, há a possibilidade de se mudar de destino para outros semelhantes ou até não viajar.

Quando impossibilitado da distribuição direta dos produtos turísticos, em função da distância geográfica, podem-se escolher canais de distribuição apropriados. O processo de comercialização poderá acontecer de três formas: diretamente pelo operador aos consumidores; utilizar intermediários como as operadoras turísticas e agências de viagens ou optar pela venda simultânea com venda direta e com intermediários (BENI, 2008, p.202).

Para Boullón (2002), a oferta de produtos, quando não consumida dentro de determinado tempo, pode ser estocada, considerando-se as condições apropriadas. Nas atividades de serviços, que é o caso do turismo, isto não é possível, pois a cada vez que expira o tempo de duração de um serviço, sua oferta é renovada e o serviço não vendido é perdido. Assim, um serviço só passa a ser produto depois de consumido, antes, é apenas oferta. Organizar e promover a venda da oferta turística de uma determinada região, país, zona, centro turístico ou atrativos é condição básica para o êxito do desenvolvimento e deve fazer parte do planejamento turístico dos mesmos.

O encontro da oferta com a demanda turística se dá por meio do processo de compra e venda, lembrando que, no turismo, o consumidor se desloca ao local geográfico em que se localiza a oferta, e não ao contrário (BOULLÓN, 2002).

Para Beni (2008), no mercado do turismo, os produtos não são homogêneos e intercambiáveis, mas diferenciados, pois, cada um vende um produto que, de certo modo, é diferenciado dos demais, o que poderia se assemelhar a um monopólio, em função desta diferenciação. Em função disso, o mercado tem certa capacidade de variar os preços, ou seja, as pessoas estão dispostas a pagar um pouco mais por um produto melhor, ou por visitar um local espetacular. Por outro lado, se os preços subirem demais, há a possibilidade de se mudar de destino para outros semelhantes ou até não viajar.

O Programa de Regionalização do Turismo - Roteiros do Brasil, MTur (2008a) entende por produto turístico o conjunto de atrativos, equipamentos e serviços turísticos, acrescidos de facilidades, localizados em um ou mais municípios, ofertado de forma organizada, por um determinado preço. Para Beni (2008), o produto turístico é um 
conjunto de bens e serviços produzidos em diversas unidades econômicas, que sofre uma agregação no mercado ao serem postos em destaques os atrativos turísticos.

O turista compra certos produtos para satisfazer suas necessidades elementares de dormir, comer e se deslocar, mas sua verdadeira motivação é o de realizar outras atividades, que lhe permitam passear, visitar os atrativos, fazer esportes e se divertir (BOULLÓN, 2002).

Os serviços turísticos vendidos são elaborados por um subsistema denominado "empreendedorismo turístico", integrado por dois elementos: Equipamentos e as Instalações. Boullón (2002) afirma, ainda, que estes, por sua vez, têm suas classificações próprias, ou seja, cada categoria de equipamentos e instalações são compostos por vários tipos, públicos e privados. Os atrativos turísticos são a matériaprima do turismo. Sem eles, a região não pode realizar o desenvolvimento turístico, porque lhe faltaria o essencial, e é partir da sua presença que se podem construir empreendimentos turísticos e explorá-los comercialmente.

Para que o turismo possa funcionar, é necessário acrescentar a infraestrutura aos atrativos e aos empreendimentos turísticos. Para o MTur (2008a), a infraestrutura básica de apoio ao turismo corresponde ao conjunto de obras, de estrutura física e serviços, que geram boas condições de vida para a comunidade e proporcionam o desenvolvimento da atividade turística, como: sistemas de transporte, energia elétrica, serviço de abastecimento de água, arruamento, sistema de comunicação, sistema educacional.

Embora uma infraestrutura excelente e bem mantida não possa garantir o crescimento da comunidade, sua ausência é um problema sério. Ela é necessária para sustentar a qualidade de vida e apoiar a produtividade econômica (KOTLER et al., 2007).

A infraestrutura pode ser dividida em externa e interna. Externa é a infraestrutura que serve a todos os setores sem pertencer a nenhum deles especificamente e se fundamenta por redes ou elementos de um sistema que se estende por um território, enlaçando centros de produção, redes de comunicação e conglomerados urbanos. A infraestrutura interna apresenta-se de duas formas: a primeira corresponde à infraestrutura que um setor dá a si mesmo, para operar em um local específico. A outra é a infraestrutura urbana que atende a todos internamente e não somente a determinado setor (BOULLÓN, 2002).

Para Boullón (2002), a fim de que o sistema de turismo funcione adequadamente, há a necessidade que, além da infraestrutura, exista um subsistema 
superior que regule todo o sistema, denominado de superestrutura. Ela compreende todos os organismos especializados, públicos e privados, encarregados de otimizar e modificando funcionamento de cada uma das partes que integram o sistema, quando necessário.

O autor afirma, ainda, que uma superestrutura, poderosa e sobre tudo eficiente, é mais importante do que se pensa, para que o setor turístico renda em relação direta com a importância dos atrativos e dos empreendimentos que se construiu para explorá-los, podendo, quanto à responsabilidade organizacional, ser composta por dois diferentes tipos de agrupamento: a) As dependências da administração pública; b) As organizações privadas. Uma das principais funções da superestrutura é não apenas vigiar, mas intervir ativamente no processo de venda do produto turístico.

\section{Patrimônio Turístico}

Para o MTur (2008b), o patrimônio é composto pelos bens de natureza material e imaterial que expressam ou revelam a memória e a identidade das populações e comunidades. São bens culturais, de valor histórico, artístico, científico, simbólico, passíveis de atração turística: arquivos, edificações, conjuntos urbanísticos, sítios arqueológicos, ruínas; museus e outros espaços destinados a apresentação ou complementação de bens materiais e imateriais; manifestações, como música, gastronomia, artes visuais e cênicas, festas e outras. Os eventos culturais englobam as manifestações temporárias enquadradas ou não na definição de patrimônio. Incluem-se nesta categoria, os eventos religiosos, musicais, de dança, de teatro, de cinema, gastronomia, exposição de arte, de artesanato e outros.

Boullón (2002) esclarece que o patrimônio turístico de um país é determinado a partir da integração de quatro componentes: atrativos turísticos, empreendimentos turísticos, infraestrutura e superestrutura turística. O autor define, ainda, patrimônio turístico como a relação entre a matéria-prima (atrativos turísticos), o empreendimento turístico (aparato produtivo), a infraestrutura turística (recursos de apoio ao aparato produtivo) e a superestrutura (subsistema organizacional e recursos humanos disponíveis para operar o sistema) detalhado na Figura 2.

Figura 2: Elementos que compõe o Patrimônio Turístico 


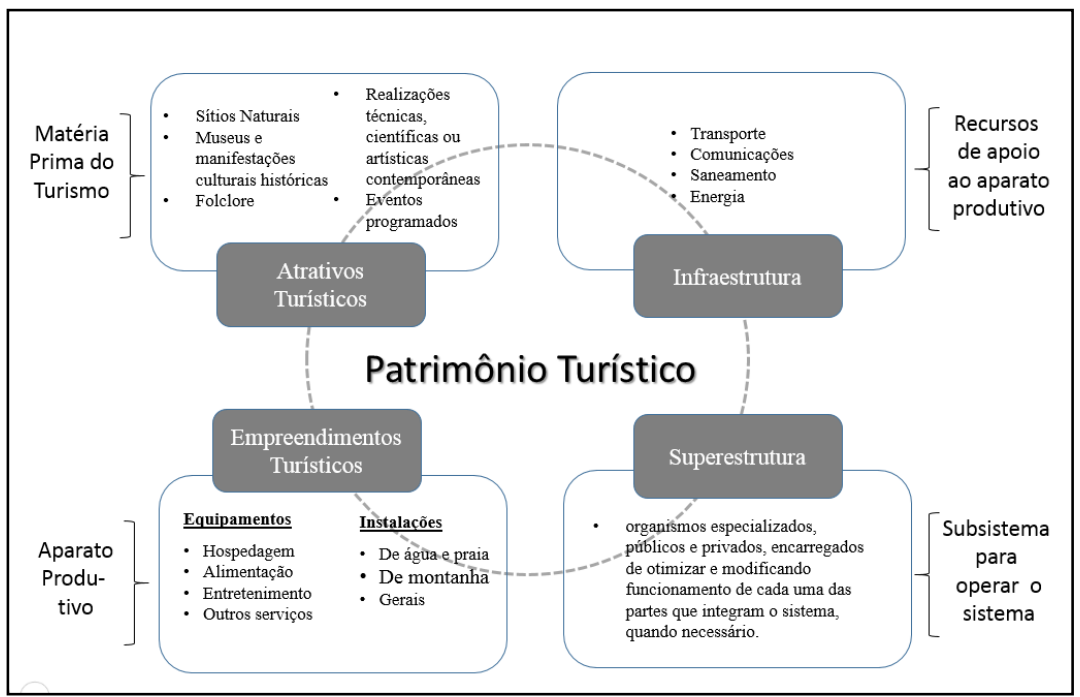

Fonte: adaptado de Boullón (2002, p.66)

\section{Espaço Turístico}

O espaço turístico é aquele em se encontram alocados os atrativos turísticos, os empreendimentos turísticos e a infraestrutura básica de apoio ao turismo. Para Beni (2008), o espaço turístico é consequência da presença e distribuição territorial dos atrativos turísticos (matéria-prima do turismo), que mais o empreendimento e a infraestrutura turística, são suficientes para definir o espaço turístico de qualquer país.

O planejamento do espaço físico apresenta-se em diferentes tipos: real, potencial, cultural, natural, virgem e artificial. Uns correspondem a diferentes expressões materiais do espaço (cultural, natural, virgem, artificial), outros são conceituações para o planejamento (real e potencial) e um deles é do campo ecológico vital (BOULLÓN, 2002). Para uma melhor compreensão, o quadro 6 apresenta uma definição sucinta de cada um dos sete tipos de espaços.

Quadro 1: Definição dos tipos de espaços para o Planejamento Turístico

\begin{tabular}{|l|l|}
\hline \multicolumn{1}{|c|}{ Tipo } & \multicolumn{1}{c|}{ Definição } \\
\hline Espaço Real & $\begin{array}{l}\text { Superfície do planeta e a biosfera que o envolve e que pode ser percebida } \\
\text { pelos sentidos do homem. Existe e pode deslocar-se por ele e modificá-lo. }\end{array}$ \\
\hline Espaço Potencial & $\begin{array}{l}\text { Potencial que o espaço real tem para o uso, deferente do atual. Não existe no } \\
\text { presente, pertence à imaginação, a um possível futuro. }\end{array}$ \\
\hline Espaço Cultural & Crosta terrestre que sofreu modificações pelo homem. \\
\hline Espaço Natural Adaptado & $\begin{array}{l}\text { Crosta terrestre em que predominam espécies vegetais, animais e minerais, } \\
\text { sob condições alteradas pelo homem (Espaço rural). }\end{array}$ \\
\hline Espaço Artificial & $\begin{array}{l}\text { Crosta terrestre em que predominam artefatos construídos pelo homem } \\
\text { (espaço urbano). }\end{array}$ \\
\hline Espaço Natural Virgem & Espaço natural sem vestígios da ação do homem. \\
\hline Espaço Vital & $\begin{array}{l}\text { Não se refere ao solo, mas ao espaço e seu entorno, necessário à existência de } \\
\text { uma espécie. }\end{array}$ \\
\hline
\end{tabular}


Fonte: Adaptado de Beni (2008)

\section{Procedimentos Metodológicos}

A pesquisa caracterizou-se como quantitativa e descritiva, uma vez que procurou reproduzir em números, percentuais e tabelas o potencial dos atrativos turísticos do patrimônio histórico e cultural dos municípios da AMREC. Para Oliveira (1999), a abordagem quantitativa significa quantificar opiniões, dados, nas formas de coleta de informações, com o emprego de recursos e técnicas estatísticas e é utilizado no desenvolvimento de pesquisas descritivas, as quais têm como objetivo descrever os resultados obtidos.

A busca dos dados se deu por meio da pesquisa de campo e método levantamento. Oliveira (1999) relata que a pesquisa de campo consiste na observação dos fatos tal como ocorrem espontaneamente, na coleta de dados e no registro de variáveis presumidamente para posterior análise. O método levantamento, de acordo com Gil (1996), caracteriza-se pela interrogação direta das pessoas cujo comportamento se deseja conhecer, procedendo-se à solicitação de informações acerca do problema estudado, para, em seguida, mediante análise quantitativa, observar-se as conclusões correspondentes aos dados coletados.

Gil (1996) afirma que as principais vantagens dos levantamentos são: conhecimento direto da realidade - à medida que as próprias pessoas informam acerca de seu comportamento, crenças e opiniões; economia e rapidez - quando os dados são obtidos mediantes questionários, os custos tornam-se relativamente baixos; quantificação - pois os dados podem ser agrupados em tabelas, possibilitando a sua análise estatística. Por outro lado, as limitações deste tipo de pesquisa estão relacionadas à ênfase nos aspectos perceptivos, pois recolhem dados referentes à percepção que as pessoas têm acerca de si mesmas, a pouca profundidade no estudo da estrutura e dos processos sociais e a visão estática do fenômeno estudado, que pode representar uma fotografia de determinado problema em determinado tempo.

O pesquisador visitou os 12 municípios da AMREC (Balneário Rincão; Cocal do Sul; Criciúma; Forquilhinha; Içara; Lauro Müller; Morro da Fumaça; Nova Veneza; Orleans; Siderópolis; Treviso e Urussanga), durante o mês de julho de 2014, com reuniões agendadas com o responsável pela operacionalização do turismo em cada um dos municípios pesquisados. 
Cabe ressaltar que, como a estrutura organizacional do turismo em cada município apresenta diferentes composições na hierarquia do poder, houve variação na nomenclatura dos cargos ocupados pelos respondentes, prevalecendo: Secretário Municipal, Presidente de Fundação Cultural, Diretor de Turismo, Assessor de Turismo e Turismólogo, porém, todos respondiam pela operacionalização das atividades turísticas dos municípios no momento da pesquisa.

O instrumento utilizado nesta pesquisa foi o desenvolvido pelo Sistema de Inventariação da Oferta Turística - INVTUR, do Ministério do Turismo, o qual foi adaptado incluindo questões relacionadas à infraestrutura de apoio, à superestrutura, a serviços e equipamentos ou atrativos turísticos.

\section{Resultados}

A pesquisa identificou e quantificou o potencial dos atrativos turísticos do patrimônio histórico e cultural dos municípios da AMREC, com base nas informações prestadas pelos responsáveis do turismo nos doze municípios pesquisados.

Os dados obtidos representam o ambiente percebido pelos responsáveis do turismo dos municípios, podendo não representar em algum aspecto o ambiente real, demonstrando de qualquer forma o potencial dos atrativos turísticos do patrimônio histórico e cultural dos municípios da AMREC. Para Bowditch e Buono (1997), o ambiente real (objetivo) consiste das entidades, objetivos e concepções que existem fora da organização, que é mensurável e externa a mesma. Já o ambiente percebido reflete a interpretação subjetiva do ambiente real. É importante destacar que as pessoas reagem em função de suas percepções do ambiente real e muitos teóricos defendem que o ambiente percebido é mais importante que o ambiente real. Tanto o ambiente real como o ambiente percebido são aspectos importantes da análise ambiental que devem ser explicitamente reconhecidos nas tomadas de decisão.

Cabe esclarecer que os dados do município de Içara foram fornecidos parcialmente, uma vez que a responsável pela área de turismo do município prestou as informações que tinha domínio e responsabilidade. As demais solicitações foram encaminhadas por ela aos outros setores da administração municipal, que não responderam a todos os quesitos a tempo. Assim, o município de Içara contribui para a presente pesquisa com dados parciais. 


\section{Atrativos Turísticos}

A Figura 3 apresenta a quantidade de atrativos naturais que os municípios da AMREC possuem, na percepção dos responsáveis pelo turismo dos respectivos municípios.

Figura 3: Distribuição dos Atrativos Naturais

\begin{tabular}{|c|c|c|c|c|c|c|c|c|c|c|c|c|c|}
\hline Tipo & 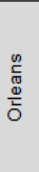 & 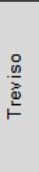 & 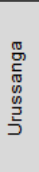 & 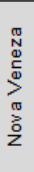 & 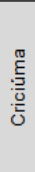 & 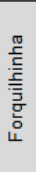 & $\begin{array}{l}\bar{\Xi} \\
\text { on } \\
\text { 음 } \\
\overline{0} \\
\text { ठ } \\
0\end{array}$ & 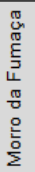 & 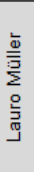 & 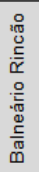 & $\begin{array}{l}\frac{n}{\overline{0}} \\
\frac{0}{0} \\
\frac{\omega}{0} \\
\bar{\omega}\end{array}$ & 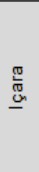 & $\begin{array}{l}\frac{\pi}{\pi} \\
\frac{\pi}{2} \\
\frac{\pi}{\pi} \\
\frac{\pi}{0}\end{array}$ \\
\hline Montanhas & 4 & 1 & 3 & 1 & 2 & 0 & 1 & 0 & 4 & 0 & 3 & 0 & 19 \\
\hline Planaltos e Planícies & 0 & 0 & 1 & 1 & 0 & 0 & 2 & 0 & 2 & 0 & 2 & 0 & 8 \\
\hline Costas ou Litoral & & & & & & & & & & 1 & & & 1 \\
\hline Hidrografia & 2 & 3 & 8 & 3 & 0 & 0 & 3 & 0 & 2 & 10 & 9 & 2 & 42 \\
\hline Quedas-d'água & 2 & 0 & 2 & 3 & 0 & 0 & 2 & 0 & 3 & 0 & 7 & 0 & 19 \\
\hline Unidades de Conservaçấ & 2 & 0 & 1 & 1 & 0 & 0 & 0 & 0 & 4 & 0 & 2 & 1 & 11 \\
\hline Cavernas/Grutas/Furnas & 0 & 0 & 0 & 1 & 1 & 0 & 0 & 0 & 1 & 0 & 6 & 0 & 9 \\
\hline Áreas de Caça e Pesca & 0 & 0 & 0 & 0 & 0 & 0 & 0 & 0 & 0 & 3 & 0 & 0 & 3 \\
\hline Flora & 0 & 0 & 0 & 2 & 2 & 1 & 0 & 2 & 2 & 0 & 1 & 2 & 12 \\
\hline Fauna & 0 & 0 & 0 & 3 & 0 & 0 & 0 & 0 & 1 & 0 & 6 & 0 & 10 \\
\hline Total por Município & 10 & 4 & 15 & 15 & 5 & 1 & $\begin{array}{llll}8 & & & \\
\end{array}$ & 2 & 19 & 14 & 36 & 5 & 134 \\
\hline
\end{tabular}

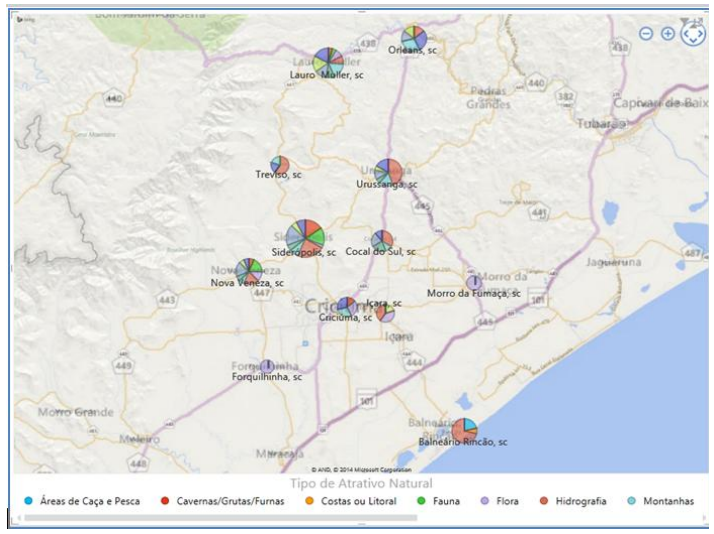

Fonte: Dados da Pesquisa

Nos atrativos naturais apontados pelos municípios, observa-se que a região possui quantidade e variedade, incluindo montanhas, planícies, litoral, hidrografia (rios e lagoas), conforme demonstra Figura 3. Em função da proximidade com a unidade geomorfológica Serra Geral e alguns dos municípios pesquisados fazerem parte do chamado "Costão da Serra", observa-se uma predominância de atrativos como montanhas, planalto e planícies, hidrografia, quedas d'água, unidades de conservação, cavernas, flora e fauna.

Ao analisarmos a concentração de atrativos naturais distribuídos nos municípios e em função do acima mencionado, pode-se observar (Figura 3 - mapa) que há uma rota natural envolvendo os municípios de Orleans, Lauro Müller, Urussanga, Siderópolis e Nova Veneza. É visível nesta constatação a proximidade destes municípios com a Serra do Rio do Rastro.

Boullón (2002) afirma que, para haver uma zona turística, deve-se ter no mínimo dez atrativos turísticos suficientemente próximos, sem importar a que tipo e a que categoria pertençam. Ao observar a quantidade e a proximidade dos atrativos encontrados, verifica-se a existência de uma zona turística bem diversificada, destacamse: serras, montes, picos; planalto e planícies; costa e litoral (13 km); rios, lagoas e quedas-d'água; unidades de conservação federal, estadual, municipal e particulares, além da flora e da fauna encontrada em toda a região. 
Acerca dos atrativos culturais - Figura 4 - da região, eles são variados, podendose destacar as festas e celebrações, religiosas e populares, que totalizam 45 ocorrências na região, as edificações (104), o número de Instituições Culturais (30), Música e Dança (53) e a gastronomia típica (23).

Figura 4: Distribuição dos Atrativos Culturais

\begin{tabular}{|c|c|c|c|c|c|c|c|c|c|c|c|c|c|}
\hline Tipo & 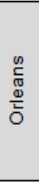 & 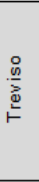 & 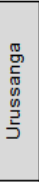 & 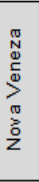 & $\frac{\stackrel{\pi}{5}}{\stackrel{\Xi}{0}}$ & 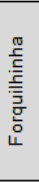 & 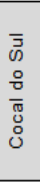 & 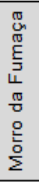 & 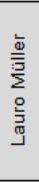 & 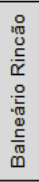 & $\begin{array}{l}\frac{n}{\overline{0}} \\
\frac{0}{0} \\
\frac{0}{0} \\
\overline{0}\end{array}$ & 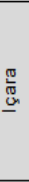 & 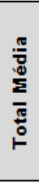 \\
\hline Sítios Históricos & 2 & 0 & 3 & 1 & 0 & 1 & 1 & 0 & 0 & 0 & 0 & 0 & 8 \\
\hline Edificações & 1 & 2 & 70 & 3 & 3 & 0 & 3 & 0 & 4 & 8 & 10 & 0 & 104 \\
\hline Obras de Arte & 3 & 1 & 10 & 3 & 3 & 0 & 4 & 0 & 2 & 0 & 5 & 0 & 31 \\
\hline Instituições Culturais & 5 & 1 & 6 & 3 & 6 & 1 & 3 & 0 & 3 & 1 & 1 & 0 & 30 \\
\hline Festas e Celebrações & 3 & 5 & 4 & 9 & 6 & 2 & 7 & 2 & 3 & 5 & 4 & 0 & 50 \\
\hline Gastronomia Típica & 0 & 1 & 0 & 1 & 7 & 1 & 5 & 0 & 5 & 2 & 1 & 0 & 23 \\
\hline Artesanato & 0 & 0 & 1 & 1 & 4 & 1 & 0 & 1 & 6 & 3 & 0 & 0 & 17 \\
\hline Música e Dança & 7 & 0 & 3 & 6 & 7 & 3 & 4 & 0 & 6 & 4 & 13 & 0 & 53 \\
\hline Feiras e Mercados & 0 & 1 & 1 & 1 & 1 & 1 & 1 & 0 & 1 & 0 & 1 & 0 & 8 \\
\hline Saberes e Fazeres & 0 & 0 & 0 & 1 & 0 & 0 & 0 & 0 & 0 & 0 & 0 & 0 & 1 \\
\hline Total por Município & 21 & 11 & 98 & 29 & 37 & 10 & 28 & 3 & 30 & 23 & 35 & 0 & 325 \\
\hline
\end{tabular}

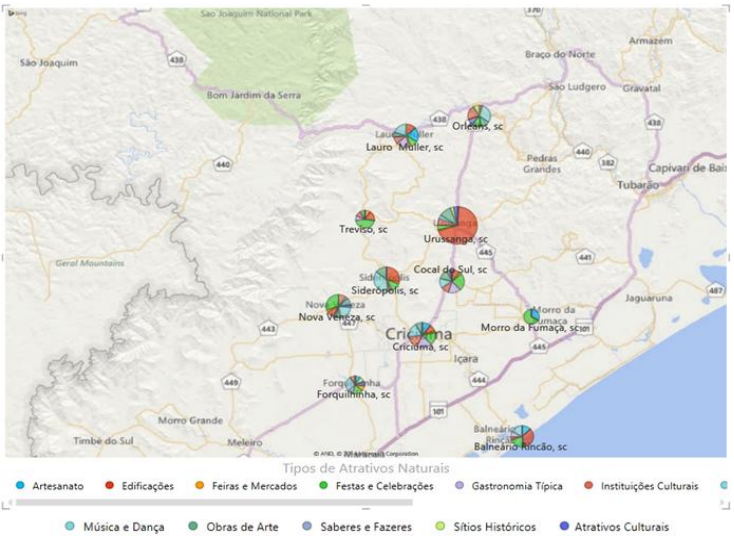

Fonte: Dados da Pesquisa

$\mathrm{Na}$ Figura 4, nota-se a distribuição dos elementos culturais nos municípios da região. Há, basicamente, uma equivalência no número de elementos entre a maioria dos municípios da AMREC. O que sobressai nos atrativos culturais, e foge da normalidade, é o número de edificações (arquitetura civil) encontrado no município de Urussanga, representadas por 70 prédios, dos quais 25 são tombados.

De acordo com o Jornal Vanguarda (2009), a maior parte das edificações encontra-se no entorno da Praça Anita Garibaldi. São 24 edificações tombadas pela Fundação Cultural Catarinense e uma pelo município. Urussanga é considerada pelo Instituto do Patrimônio Histórico e Artístico Nacional (IPHAN) a cidade mais representativa de Santa Catarina no que se refere ao cenário urbano, identificado com a imigração italiana.

Por outro lado, a variedade dos atrativos culturais na região é um facilitador à integração, em função das peculiaridades e diversidade em cada município. A complementariedade desses elementos facilita e possibilita da criação de rotas turísticas, podendo integrar festas, visitas a edificações, gastronomias, dentre outras possibilidades. A criação de um calendário unificado e integrado de festa é fundamental para a alavancagem do turismo da região.

É importante destacar que a matéria-prima do turismo, conforme define Boullón (2002), são os atrativos turísticos e que a região dispõe de quantidade e variedade desta matéria-prima. Do ponto de vista dos atrativos naturais, estes se concentram nos 
municípios com maior proximidade com a Serra Geral (Figura 4 - mapa), porém, do ponto dos atrativos culturais, a distribuição é mais homogênea na região estudada. Essa integração entre as possibilidades de oferta turística por meio dos atrativos naturais, integrados com os culturais, criando-se rotas integradas e calendários culturais adequados, pode ser o elemento propulsor do turismo regional com maior potencial de retenção do turista na região, prolongando sua estada.

Foram verificados também os tipos de atividades, podendo representar a diversificação da econômica dos municípios da região, uma vez que a atividade econômica é um fator importante no movimento turístico, incentivando o segmento do turismo de negócios, por meio de feiras, exposições, viagens de negócios e outros. $\mathrm{Na}$ região estudada, foram identificadas diferentes atividades no segmentos de: 11 de extrativismo e exploração, 25 de agropecuária e 46 de indústria.

Sobre os eventos permanentes, foram identificados 48 eventos permanentes na região, nas mais diversas áreas, passando por Congressos e Convenções (1), Feiras, Exposições (15), Realizações Desportivas (19), artísticas (6), sociais (2) e gastronômicas (5), cuja concentração é maior nos municípios de Criciúma, Cocal do Sul e Siderópolis respectivamente com 11, 9 e 11 atividades.

\section{Serviços e Equipamentos Turísticos}

A fim de tornar a análise consistente, é necessária a apreciação de bens e serviços, como recreação, lazer, alojamento e alimentação que tenham potencial de atração turística, esclarece Beni (2008). Acerca dos estabelecimentos e vagas nos meios de hospedagem das cidades pesquisadas, cadastradas ou conhecidas pelos entrevistados, com possibilidades de serem usadas com fins turísticos. Os resultados apresentaram: 29 hotéis com 2656 vagas, 25 Campings com 2260 vagas, 16 motéis com 588 vagas, 15 pensões com 371 vagas, 11 pousadas com 211 vagas, 1 resort com 70 vagas totalizando 157 estabelecimentos com 6156 vagas.

Verificando geograficamente, pode-se observar que a representatividade dos municípios de Balneário Rincão, Siderópolis e Treviso, deve-se às vagas em campings, as quais são vagas sazonais, utilizadas principalmente no verão para um tipo específico de turismo. Fica evidenciado que a cidade de Criciúma - 2.102 vagas distribuidas em 25 estabelecimentos, polo regional, detém a maior rede de hospedagem da região, o que fortalece o desenvolvimento do turismo como uma atividade integrada e de abrangência regional. 
No ramo da alimentação, identificados como estabelecimentos com interesse turístico, podem-se destacar as cidades de Criciúma que conta com 287 estabelecimentos e os municípios de: Nova Veneza (24), Siderópolis (20) e Urussanga (47), despontando com estabelecimentos focados na gastronomia Italiana, com qualidade e potencial turístico, atrelados à cultura italiana deixada pelos colonizadores da região, que vieram, principalmente, da região do Vêneto, na Itália.

$\mathrm{Na}$ análise dos serviços de apoio direto ao turismo, na região estudada, foram identificadas 22 agências de viagens, das quais 12 estão alocadas em Criciúma. Sobre os serviços de transporte, foram localizadas 18 transportadoras turísticas (5 em Criciúma) e 6 locadoras de veículos (3 em Criciúma) e 259 táxis distribuídos na região exceto nas cidades de Treviso e Nova Veneza, destes 200 na cidade de Criciúma. Há também as opções de transporte rodoviário. O transporte urbano nos municípios pesquisados não é um facilitador para um turista que deseja se locomover autonomamente, sem utilizar um veículo particular. Com exceção de Criciúma, que possui um sistema integrado de transporte público, os municípios da AMREC que mantêm este serviço, procuram atender à população com linhas que interligam bairros distantes, com poucas rotas diárias.

De acordo com os responsáveis pelo turismo nos municípios pesquisados, na AMREC existem 460 locais para lazer e entretenimento, dos quais 206 estão concentrados em Criciúma (44,85\%). Os demais estão pulverizados nos demais municípios estudados.

Foram identificados 9 terminais rodoviários, com 75 linhas intermunicipais, 5 linhas interestaduais das quais 30 e 4 respectivamente estão na cidade de Criciúma. Relativo ao transporte aéreo, na cidade de Forquilhinha a qual pode ser considerada grande Criciúma, há 1 terminal aéreo com dois voos diários.

Com relação às instalações e serviços para eventos, há um total de 144 estabelecimentos, 51 estão alocados na cidade de Criciúma. A distribuição dessas instalações está em: 22 parques, pavilhões e exposições; 28 auditórios, teatros e salas de convenções; 4 centros de convenções; 89 clubes sociais e associações e 1 considerado como serviços.

Também foram verificadas as quantidades de empresas organizadoras (23) e prestadoras de serviços (57), sendo a maior quantidade alocada em Criciúma (15 e 22 respectivamente). 
Analisando a estrutura dos Serviços de Apoio Direto ao Turismo, pode-se verificar que a cidade de Criciúma é a que tem maior quantidade e diversidade de serviços voltados ao Turismo. Isso se deve, possivelmente, pelo fato de Criciúma ser a maior cidade do extremo Sul Catarinense e dispor de uma atividade econômica e social que requer uma estrutura adequada para atender às demandas da sociedade local e com abrangência regional. Assim, o número de agências de turismo, de equipamentos como parque, pavilhões de exposição, teatros, clubes sociais, dentre outros, é muito superior aos demais municípios da AMREC. Esse fato deve ser levado em consideração na regionalização do turismo, pois um turista, atraído para a região, pode buscar atrativos naturais e culturais que esta lhe proporciona e ter, em Criciúma, uma base para o seu deslocamento pela região, usufruindo da infraestrutura existente na cidade.

De acordo com os responsáveis pelo turismo nos municípios pesquisados, na AMREC existem 460 locais para lazer e entretenimento, dos quais 206 estão concentrados em Criciúma (44,85\%). Os demais estão pulverizados nos demais municípios da região. Este é mais um sinal da posição estratégica de Criciúma na regionalização do turismo da AMREC, que pode contribuir com infraestrutura, com locais para lazer e entretenimento, com possibilidades de compras, podendo os demais municípios da região se especializarem em suas vocações em função de seus atrativos naturais e culturais, complementando a atração para a retenção do turismo na região.

\section{Infraestrutura de Apoio ao Turismo}

Como demonstrado em situações anteriores, o município de Criciúma tem a melhor e mais variada infraestrutura para apoio à atividade do turismo na região, fazendo prevalecer a sua condição de polo regional. Na questão do transporte público regional, é importante observar que todos têm linhas troncais ligando à Criciúma, e que entre os municípios da AMREC a integração é feita prioritariamente por meio de Criciúma. Isso, se por um lado, reafirma a posição de Criciúma como cidade polo regional; por outro, demonstra a dificuldade de locomoção de turistas na região por meio do transporte público. Isto dificulta a criação de rotas que o turista possa fazer de forma autônoma e sem um veículo particular, ou seja, utilizando apenas o transporte público.

O sistema de segurança pública está estruturado para atender às demandas dos municípios pesquisados, levando em consideração o tamanho da população existente em 
cada um deles. Criciúma, como maior município da região, possui a maior e mais diversificada rede da segurança pública.

Quando ao sistema de comunicação da AMREC, nota-se a existência de sinal das quatro principais operadoras de celular do Brasil (TIM, VIVO, Claro e Oi) em quase todos os municípios (10 de 12). Todos possuem acesso à internet e estão cobertos por jornais locais e sistemas de rádio.

O sistema de saúde da AMREC tem Criciúma como referência regional, possuindo 4 hospitais dentre os 10 da região e 20 (de um total de 28) clínicas e centros especializados atendendo a maioria das especialidades médicas. Oito municípios possuem também seus sistemas adequados ao tamanho de suas populações. Nem todos os municípios possuem o Serviço de Atendimento Móvel de Urgência (SAMU), o que deve ser revisto pelos municípios que não o possuem e que querem intensificar a atividade turística em seu território. Na Figura 5, ficam evidenciadas a quantidade e variedade da infraestrutura de Criciúma para apoiar a atividade turística Regional, configurando a cidade de Criciúma como polo regional.

Figura 5: Infraestrutura Turística

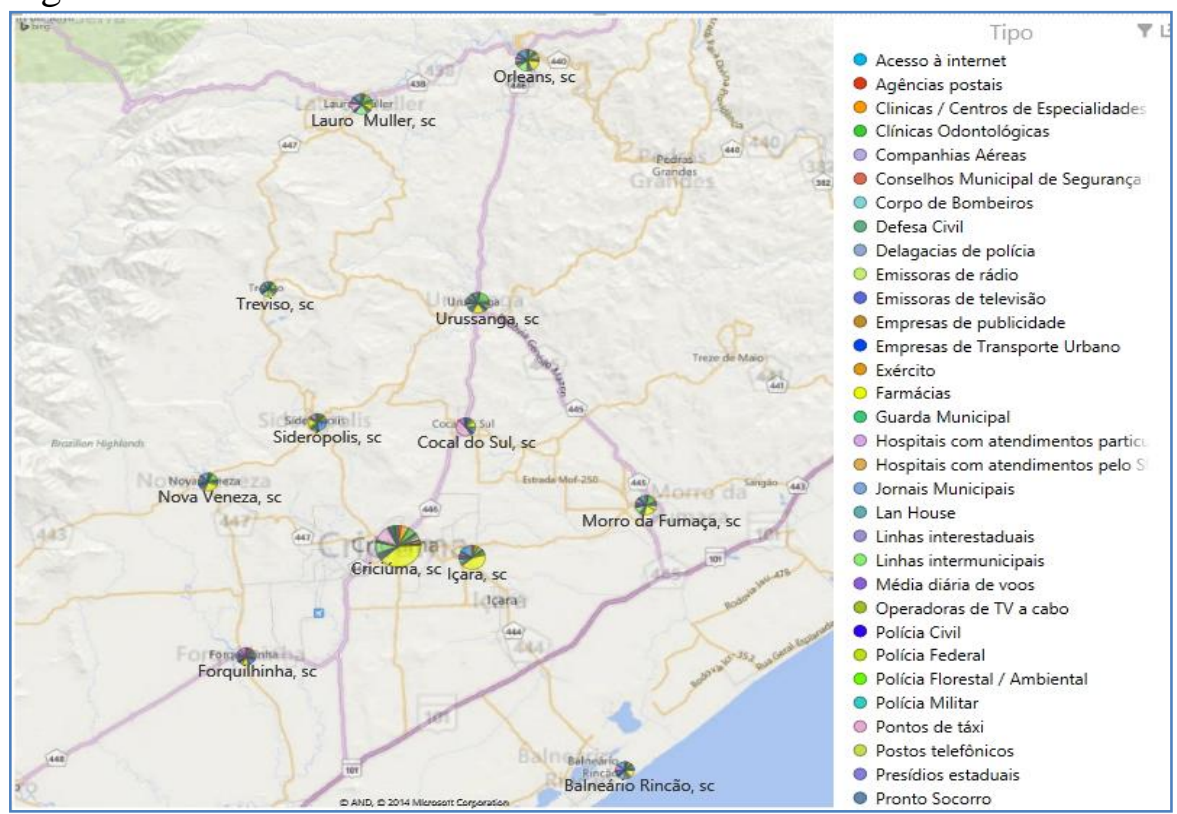

Fonte: Dados da pesquisa

\section{Sistema de Turismo Municipal}

A pesquisa identificou a maneira como os municípios se organizam, do ponto de vista organizacional. Verificou-se que nenhum dos municípios da AMREC possui uma secretaria exclusiva para atendimento as atividades turísticas. Todos têm o turismo associado a outras pastas ou à Fundação Municipal. Alguns adotam uma estrutura como 
diretoria, outros como departamento ou setores e, em alguns casos, está associado à Fundação Cultural.

A existência de uma secretaria específica não é condição primordial para que o turismo se desenvolva na região. O que importa é a forma como cada um se organiza e que exerça o papel de fomentar as atividades turísticas em seus municípios.

É importante destacar que no sistema proposto por Boullón (2002, p.38), para que ele funcione adequadamente, além da infraestrutura, há a necessidade de um subsistema auxiliar denominado superestrutura, composto por entidades públicas e privadas, encarregadas de otimizar e modificar, quando necessário, o funcionamento de cada uma das partes integrantes do sistema e harmonizar suas relações, facilitando a produção e a venda dos múltiplos e diferentes serviços.

Neste sentido, a estrutura municipal tem papel fundamental na organização, motivação, otimização, mudança cultural, dentre outros termos que são necessários ao desenvolvimento de qualquer atividade econômica e é fundamental nas atividades do turismo, que precisa funcionar em rede.

Exemplos de vinculações: Cultura e Turismo; Educação Esporte e Turismo; Educação Cultura e Turismo; Fundação Cultural.

Figura 6: Estrutura do Turismo Municipal

\begin{tabular}{|c|c|c|c|c|c|c|c|c|c|c|c|c|c|}
\hline Tipo & $\frac{\tilde{\Xi}}{\tilde{\Xi}}$ & 离 & 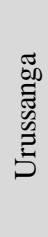 & 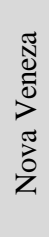 & 节 & 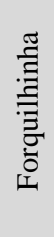 & $\begin{array}{l}\bar{\Xi} \\
\text { s } \\
\text { o } \\
\tilde{J} \\
\delta\end{array}$ & 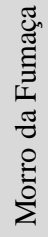 & $\begin{array}{l}\bar{\Xi} \\
\stackrel{\bar{\Xi}}{\Xi} \\
o \\
\Xi \\
\Xi \\
\Xi\end{array}$ & 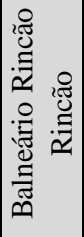 & 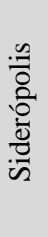 & 芯 & 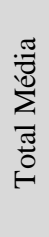 \\
\hline Secretaria de Turismo específica & & & & & & & & & & & & & 0 \\
\hline Secretaria de Turismo conjunta com outro & 1 & 1 & & 6 & & 1 & & 1 & 2 & & & & 12 \\
\hline Diretoria de Turismo & & 1 & 3 & & & & 1 & & & & & & 5 \\
\hline Departamento / Setor de Turismo / Fundaçâ & & & & & 3 & & & & & 3 & 2 & 1 & 9 \\
\hline Total & 1 & 2 & 3 & 6 & 3 & 1 & 1 & 1 & 2 & 3 & 2 & 1 & 26 \\
\hline
\end{tabular}

Fonte: Dados da Pesquisa

Apesar desta vinculação a outras áreas da administração pública municipal, todos os municípios têm, no mínimo, uma pessoa desenvolvendo atividades específicas com relação ao turismo.

Há de se destacar o município de Nova Veneza, com o maior número de colaboradores dedicados exclusivamente ao turismo, incluindo um profissional da área, o Turismólogo, totalizando 6. 
Ter profissionais especializados para tratar da atividade turística é fundamental para a profissionalização e desenvolvimento da área. Na gestão pública dos municípios pesquisados, apenas um Turismólogo foi identificado, o que mostra um grau de profissionalização muito baixo na região. Isto acaba levando ao amadorismo, à perda de oportunidades e fluxo turístico e um lento desenvolvimento da atividade.

\section{Considerações Finais}

A pesquisa realizada com os municípios da AMREC identificou ou confirmou a existência de um significativo potencial turístico na região, com base na matéria-prima do turismo: os atrativos turísticos (naturais e histórico-culturais).

A presença da unidade geomorfológica Serra Geral, com municípios fazendo parte da mesma ou situados em sua encosta, e outros aproveitando da qualidade da paisagem, proporcionam possibilidade ilimitadas de atividades turísticas ligadas à natureza, à cultura e à gastronomia. O Balneário Rincão, com seus 13 quilômetros de praias e com duas plataformas de pesca, gera uma série de possibilidades de atividades específicas no verão.

A colonização da região com predominância europeia e, principalmente italiana, com arquitetura, costumes e gastronomia marcantes, cria uma atmosfera diferenciada e convidativa ao passeio, descanso e lazer. Cidades como Nova Veneza, Siderópolis e Urussanga, vêm desenvolvendo ações, por meio do poder público e da iniciativa privada, que estão incentivando o desenvolvimento turístico nestes municípios. Isso acaba beneficiando os demais, pois o aumento do fluxo de visitantes nestas cidades gera também uma movimentação, em menor proporção, nos municípios vizinhos.

A existência de atrativos culturais com quantidade e diversidade mostram o potencial turístico de toda região, com edificações, instituições culturais, música e dança, arquitetura e, principalmente, com as festas religiosas e culturais que, anualmente, somam 50 eventos.

Quanto aos equipamentos turísticos, percebe-se que há uma concentração maior no município de Criciúma, o polo regional, e que alguns municípios estão em um processo de incentivar o desenvolvimento desses equipamentos. Porém, devido ao tamanho e à atividade econômica de muitos municípios pesquisados, fica evidente que a tendência é de que Criciúma continue como polo regional, inclusive no turismo. Isto 
possibilita aos visitantes usufruir da infraestrutura e dos empreendimentos turísticos da cidade para seu lazer e compras, porém, aproveitando as rotas regionalizadas.

Criciúma é uma cidade industrial, com um PIB que representa 45,3\% da região (IBGE, 2011), porém, os serviços representam 62,8\% de seu valor adicionado bruto, o que demonstra as possibilidades de prestação de serviços, inclusive, na área turística.

Criciúma apresenta ainda o maior sistema médico-hospitalar, de segurança, de hospedagem, de alimentação, de transporte, de oportunidades de lazer e entretenimento região.

Assim, pela pesquisa, pode-se considerar que a região tem atrativos, infraestrutura e empreendimentos turísticos para experimentar um crescimento turístico interessante. Porém, deve desenvolver suas atividades turísticas a partir da cidade polo, que detém as condições de melhor atender aos visitantes em suas necessidades básicas.

As demais cidades devem se concentrar em aprimorar e oferecer seus atrativos naturais e culturais com o maior esmero possível, cativando os visitantes, oferecendo produtos e serviços com valores agregados, que cativem o turista. Para isto, é fundamental a criação de rotas regulares e regionais, de capacitação das pessoas, de melhoramento na infraestrutura das cidades e de melhoria nas instalações.

A superestrutura, composta pelos organismos públicos e privados, devem ser atuantes e integrados regionalmente para que tudo funcione com eficiência. Para isto, terá que se profissionalizar, oportunizando vagas para profissionais do turismo nas prefeituras, casas de cultura, associações turísticas e na própria AMREC, uma vez que apenas o município de Nova Veneza apresenta um profissional da área, turismólogo.

A presente pesquisa teve por objetivo a análise quantitativa do potencial dos atrativos turísticos do patrimônio histórico e cultural dos municípios da AMREC, com base em informações prestadas pelos responsáveis do turismo nos municípios pesquisados. Partindo da premissa de que os Prefeitos da AMREC - e isso foi confirmado durante a pesquisa - têm o interesse em investir no turismo dos municípios, apontando esta atividade com uma possibilidade de desenvolvimento socioeconômico, recomenda-se:

1. Profissionalizar os setores que trabalham com o turismo nos municípios, por meio da contratação ou investindo na qualificação dos servidores que hoje atuam na área turística, inclusive com a participação de Turismólogo nas equipes técnicas; 
2. Criar um grupo de profissionais do turismo dentro da própria AMREC para prestar serviços às prefeituras, desenvolvendo as políticas e orientando a todos de forma regionalizada;

3. Realizar o inventário turístico INVTUR de todos os municípios da AMREC, utilizando-o como base para o planejamento da integração do turismo regional, além de aproximar o ambiente percebido (subjetivo) pelos operacionalizares do turismo dos municípios com o ambiente real existente (objetivo);

4. Desenvolver a superestrutura turística em todos os municípios pesquisados, capacitando e distribuindo responsabilidades aos seus integrantes, para que se tenha uma gestão eficiente sobre os atrativos turísticos do patrimônio histórico e cultural dos municípios, o que facilitaria o desenvolvimento integrado do turismo regional;

5. Integrar o turismo das cidades da AMREC como um único bloco e aproveitar toda a estrutura e infraestrutura da maior cidade do Sul Catarinense, Criciúma. Cada município deve desenvolver suas especialidades com bases nos atrativos naturais e culturais neles existentes;

6. Desenvolver as rotas regionalizadas, podendo Criciúma ser a porta de entrada dessas rotas. Estas rotas devem contemplar atividades durante todo o ano, explorando as potencialidades naturais e culturais da região;

7. Procurar utilizar uma abordagem de planejamento voltada à comunidade que, segundo HALL (2002, p.53), há a necessidade de um maior envolvimento da comunidade no turismo em suas cinco metas de desenvolvimento turístico que devem visar: 1) proporcionar uma estrutura para elevar o padrão de vida dos residentes locais por meio dos benefícios econômicos gerados pelo turismo; 2) desenvolver uma infraestrutura e oferecer instalações recreativas para residentes e visitantes; 3) assegurar que os avanços ocorridos nos centros de visitantes e resorts sejam adequados aos objetivos dessas áreas; 4) criar um programa de desenvolvimento consistente com a filosofia cultural, social e econômica; e 5) otimizar a satisfação do visitante. O planejamento turístico comunitário é uma resposta à necessidade de desenvolver diretrizes de maior aceitação social para a expansão do setor;

8. Aproveitar os dados levantados na pesquisa para melhorar as informações dos elementos do patrimônio turístico, fazendo a identificação, registro e qualificação dos atrativos turísticos do patrimônio histórico e cultural dos municípios;

9. Utilizar os dados da pesquisa como base para o estudo da cadeia produtiva do turismo dos municípios da AMREC.

\section{Referências}


AGUIAR, Marli Maria de. Vamos construir o desenvolvimento. Revista Liderança Empresarial da Associação Empresarial de Criciúma - ACIC, Criciúma SC, número 39, 2013.

ALVES, João Pedro. Idealizando o Futuro. Revista Liderança Empresarial da Associação Empresarial de Criciúma - ACIC, Criciúma SC, número 39, 2013.

AMREC, Associação dos Municípios da Região Carbonífera. Estatuto Social. 2014. Disponível em

<http://www.amrec.com.br/arquivosdb/basico1/0.996329001370871371_estatuto_social .pdf>. Acessado em 30 de julho 2014.

AQUINO, André Luiz; BRESCIANI, Luís Paulo. Arranjos produtivos locais: uma abordagem conceitual. Universidade Metodista de São Paulo: Revista Organizações em Contexto, 2005

ATLASBRASIL. Atlas do Desenvolvimento Humano do Brasil 2013. Disponível em <http://www.atlasbrasil.org.br/2013/pt/ranking>. Acessado em 31 de julho de 2014.

BARROS, Jones Nogueira; DUARTE, José Rubens Souza; LIMA, Keit Michele Martins; SANTOS, Isabel Cristina dos; TADEUCI, Marilsa de Sá Rodrigues. TURISMO: INDÚSTRIA LIMPA E DESENVOLVIMENTO LOCAL SUSTENTÁ VEL. XIII Encontro Latino Americano de Iniciação Científica e IX Encontro Latino Americano de Pós-Graduação - Universidade do Vale do Paraíba, 2009.

BENI, Mário Carlos. Análise Estrutural do Turismo. São Paulo: Editora Senac, São Paulo, 2008.

BOUllón, Roberto C. Planejamento do Espaço Turístico. Bauru, SP: EDUSC, 2002.

BOWDITCH, James L.; BUONO, Anthony F. Elementos de Comportamento organizacional. São Paulo: Ed. Pioneira, 1997. 305 p.

BRASIL. Ministério do Turismo. Secretaria de Políticas de Turismo. Programa de qualificação a distância para o desenvolvimento do turismo: Curso de Roteirização do Turismo - Livro 4. Florianópolis: SEaD/UFSC, 2008a.

BRASIL. Ministério do Turismo. Secretaria de Políticas de Turismo. Programa de qualificação a distância para o desenvolvimento do turismo: Curso de Roteirização do Turismo - Livro 2. Florianópolis: SEaD/UFSC, 2008b.

BRASIL. Ministério do Turismo. Secretaria de Políticas de Turismo. Programa de qualificação a distância para o desenvolvimento do turismo: Curso de Roteirização do Turismo - Livro 3. Florianópolis: SEaD/UFSC, 2008c.

BRASIL. Ministério do Turismo. Projeto Inventário da Oferta Turística Ministério do Turismo - Programa de Regionalização do Turismo - Roteiros do Brasil. Brasília, 2006.

BRASIL. IBGE, Instituto Brasileiro de Geografia e Estatística. Economia do turismo: uma perspectiva macroeconômica 2003-2009. Coordenação de Contas Nacionais. Rio de Janeiro: IBGE, 2012. 
BRASIL. IBGE, Instituto Brasileiro de Geografia e Estatística. Cidades. Disponível em <http://www.cidades.ibge.gov.br/xtras/home.php?lang>. Acessado em 22 de abril de 2014.

BRASIL. IBGE, Instituto Brasileiro de Geografia e Estatística. Contas Nacionais Número 40 - Contas Regionais do Brasil 2011. Rio de Janeiro: IBGE, 2013.

BRASIL. IBGE, Instituto Brasileiro de Geografia e Estatística. Sala de Imprensa. Disponível em <http://saladeimprensa.ibge.gov.br/noticias?view=noticia\&id=1\&busca=1\&idnoticia=1 293 >. Acessado em 31 de julho de 2014.

CHIAVENATO, Idalberto. Comportamento Organizacional: a dinâmica do sucesso das organizações. Rio de Janeiro: Elsevier, 2005.

COSTA, Eliezer Arantes. Gestão Estratégica: da empresa que temos a empresa que queremos. São Paulo: Saraiva, 2007.

DIAS, Reinaldo. Turismo e Patrimônio Cultural - Recursos que Acompanham o Crescimento das Cidades. São Paulo: Saraiva, 2006.

EMBRATUR. Instituto Brasileiro de Turismo. Site oficial. 2014. Disponível em

FABRE, Ademar José. Fórum de Turismo no Sul: a Sulcatur faz nova tentativa. Engeplus. 2009. Disponível em: http://www.engeplus.com.br/impressao/forum-deturismo-no-sul-a-sulcatur-faz-nova-tentativa/.

FECAM. Associações de Municípios - Mesorregiões. Disponível em <http://guia.fecam.org.br/associacoes/index.php>. Acessado em: dez. 2012.

FELISBERTO, Deize. Nova Veneza recebe novos empreendimentos. Portal Clicatribuna. Criciúma. 2013. Disponível em

$<$ http://www.clicatribuna.com/noticia/economia/nova-veneza-recebe-novosempreendimentos-7665>. Acessado em 31 de julho de 2014.

FOZ DO IGUAÇU. Prefeitura Municipal de Foz do Iguaçu. Secretaria Municipal de Turismo. Inventário da Oferta Turística. Foz do Iguaçu: SMTU, 2013

GIL, Antonio Carlos. Como elaborar projetos de pesquisa. São Paulo: Ed. Atlas, 1996.

HALL, Collin Michael. Planejamento Turístico: políticas, processos e relacionamentos. São Paulo: Contexto, 2001.

IPEADATA. Glossário. Disponível em

<www.ipeadata.gov.br/doc/Contas\%20Nacionais-Conceitos.doc> Acessado em 31 de julho de 2014.

Jornal Vanguarda. Casas tombadas, patrimônio histórico de Urussanga, Jornal Vanguarda, fev. 2009.

Disponível em http://www.jvanguarda.com.br/site2012/2009/02/05/casastombadaspatrimonio-historico-de-urussanga/

KOTLER, Philip at al. Marketing de Lugares: Como conquistar crescimento de longo prazo na América Latina e no Caribe. São Paulo: Prentice Hall. 2007. 340p. 
LIMA, Andréia. Amrec projeta investimento regional em turismo. Jornal da manhã, p. 7. Jul/2014. Disponível em:

http://www.diariosapp.com.br/fmanager/jdiarios/edicoes/arquivo4330_1.pdf

Ministério do Turismo. Planejamento e Gestão. Brasília. Disponível em: <http://www.turismo.gov.br/turismo/programas_acoes/planejamento_gestao/>. Acesso em: dez. 2012.

Ministério do Turismo. Coordenação Geral de Regionalização. Programa de Regionalização do Turismo - Roteiros do Brasil : Módulo Operacional 7 Roteirização Turística/ Ministério do Turismo. Secretaria Nacional de Políticas de Turismo. Departamento de Estruturação, Articulação e Ordenamento Turístico. Coordenação Geral de Regionalização. Brasília, 2007.

MTur. Ministério do Turismo. INVTUR - Sistema de Inventariação do Sistema Turístico. Brasília: $\quad$ INVTUR, 2014. Disponível em <http://www.inventario.turismo.gov.br/invtur/swfs/prototipoVisitante.html>. Acessado em 2014.

MTur. Ministério do Turismo. Plano Nacional de Turismo 2013 - 2016 - "O Turismo fazendo muito mais pelo Brasil”. Brasília: MTur, 2013.

MTur. Ministério do Turismo. Site oficial. Disponível em

$<\mathrm{http}: / / \mathrm{www}$. turismo.gov.br>

Prefeitura de Criciúma. Comemorado dez anos de Gemellaggio. 2011. Disponível em

$<$ http://www.criciuma.sc.gov.br/site/noticia/comemorado_dez_anos_de_gemellaggio-

5617.> Acessado em 31 de julho de 2014.

NETO, Luís Moretto; AGOSTINI, Julio Cezar. Caminhos: turismo integrado ao lago de Itaipu: um exercício de cidadania para o desenvolvimento sustentado. Florianópolis: [s.n.], 2005. 183 p.

OlIVEIRA, Silvio Luiz de. Tratado de Metodologia Científica. Projetos de Pesquisa, TGI, TCC, Monografias, Dissertações e Teses. São Paulo: Pioneira Thomson Learning, 2002.

PEARCE, Douglas G.; BUTLER, Richard W. Desenvolvimento em turismo - Temas contemporâneos. São Paulo: Contexto, 2002.

RIBEIRO, Marcelo. Desenvolvimento regional, turismo e educação ambiental. Organização de Roberto Verdum, Tânia Marques Strohaecker

Porto Alegre: Organização de Associação dos Geógrafos Brasileiros, 2000.

RODRIGUES, Adyr A.B. Turismo e Geografia - Reflexões Teóricas e Enfoques Regionais. São Paulo: Hucitec, 1999.

SANTUR. Santa Catarina Turismo S/A. Disponível em

<http://turismo.sc.gov.br/institucional/index.php/pt-br/> . Acessado em dez 2012.

SATC. Potencial turístico do sul desponta como indústria promissora para o desenvolvimento. Portal Veneza. 2014. Disponível em <http://www.portalveneza.com.br/potencial-turistico-sul-desponta-como-industriapromissora-para-desenvolvimento/>. Acessado em junho de 2014 
Revista Tecnologia e Ambiente, v. 22, 2016, Criciúma, Santa Catarina

ISSN 1413-8131

SOL - Secretaria de Estado de Turismo, Cultura e Esporte. Florianópolis. Disponível em:

$<$ http://www.sol.sc.gov.br/index.php?option=com_content\&view=article\&id=54\&Itemi $\mathrm{d}=65>$. Acesso em : dez. 2012. 